\title{
Lapatinib-induced mesenchymal-epithelial transition in squamous cell carcinoma cells correlates with unexpected alteration of $\boldsymbol{\beta}$-catenin expression
}

\author{
CLAUDIA UMBREIT ${ }^{1}$, PHILIPP ERBEN ${ }^{2}$, ANNE FABER $^{1}$, RALF-DIETER HOFHEINZ $^{3}$, \\ JOHANNES DAVID SCHULTZ ${ }^{1}$, KARL HOERMANN ${ }^{1}$ and ANGELA WENZEL ${ }^{1}$
}

Departments of ${ }^{1}$ Otorhinolaryngology, Head and Neck Surgery, ${ }^{2}$ Urology and ${ }^{3}$ Hematology and Oncology, University Medical Centre Mannheim, Medical Faculty Mannheim, University of Heidelberg, D-68167 Mannheim, Germany

Received December 12, 2014; Accepted October 14, 2015

DOI: $10.3892 / \mathrm{ol} .2016 .4293$

\begin{abstract}
The epithelial-mesenchymal transition (EMT) is a key developmental program that is often activated during cancer progression, and may promote resistance of cancer cells to therapy. Inhibiting EMT appears to be crucial to inhibit drug resistance. The mesenchymal-epithelial transition (MET), which is the reverse program of EMT in metastases, is characterized by the upregulation of epithelial adhesive proteins such as E-cadherin, and downregulation of mesenchymal proteins such as vimentin. The sensitivity of cancer cells to epithelial growth factor receptor (EGFR) inhibitor may be increased by inducing MET in these cells. Therefore, it is of clinical importance to specify the phenotype of cancer cells in order to overcome the phenomenon of drug resistance. The aim of the present study was to investigate the expression pattern of specific markers in squamous cell carcinoma (SCC) cells following stimulation with lapatinib and gefitinib. For this purpose, the head and neck (HN) SCC cell lines HNSCC22B and HNSCC11A were incubated with 0.5 and $2 \mu \mathrm{g} / \mathrm{ml}$ lapatinib and gefitinib, and the levels of E-cadherin, vimentin, matrix metalloproteinase-14, c-kit and $\beta$-catenin were detected by immunocytochemistry and enzyme-linked immunosorbent assay at 5,24 and $96 \mathrm{~h}$ post-incubation. The results indicated that, compared with HNSCC22B cells, the protein expression levels of vimentin increased, whereas those of E-cadherin reduced, in non-stimulated HNSCC11A cells. In addition, the protein expression levels of $\beta$-catenin
\end{abstract}

Correspondence to: Dr Claudia Umbreit, Department of Otorhinolaryngology, Head and Neck Surgery, University Medical Centre Mannheim, Medical Faculty Mannheim, University of Heidelberg, 1-3 Theodor-Kutzer-Ufer, D-68167 Mannheim, Germany E-mail: claudia.umbreit@web.de

Key words: mesenchymal-epithelial transition, lapatinib, gefitinib, $\beta$-catenin, vimentin, E-cadherin, matrix metalloproteinase-14, c-kit, head and neck squamous cell carcinoma, epithelial-mesenchymal transition were altered in the epithelial- and mesenchymal-associated SCC cell lines following treatment with lapatinib and gefitinib. Furthermore, lapatinib induced the downregulation of vimentin and upregulation of E-cadherin in HNSCC11A cells in a time-dependent manner. This suggests that the sensitivity of cancer cells to lapatinib may be improved by inducing MET in these cells. In summary, the results of the present study demonstrated that lapatinib-induced MET led to an unexpected alteration of the protein expression levels of $\beta$-catenin in SCC cells. Further studies on the mechanistic role of MET are required in order to increase the sensitivity of cancer cells to EGFR inhibitor and block the EMT process in these cells.

\section{Introduction}

Head and neck squamous cell carcinomas (HNSCCs) are the sixth most common cause of cancer-associated mortality worldwide (1). Epidermal growth factor receptor (EGFR), also known as HER1 or ErbB1, is a member of the human EGFR tyrosine kinase family, which induces cell growth, proliferation, survival and dedifferentiation in a variety of tissues via the EGFR signalling pathway (2). However, aberrant EGFR-signalling occurs in $>90 \%$ of HNSCCs during the oncogenic process (3). In addition, overexpression of EGFR correlates with tumour spread, poor survival and resistance to radiotherapy and chemotherapy $(3,4)$. Concurrent chemoradiation (CRT) has been associated with improved locoregional control and organ preservation, but it causes acute and chronic toxicity. Molecular target therapies specifically directed to EGFR may improve the outcomes of patients with HNSCC while offering lower toxicity than traditional treatments (1). Thus, the development of monoclonal antibodies or agents that inhibit EGFR or its tyrosine kinase is of clinical relevance (5). In this context, cetuximab (Erbitux ${ }^{\circledR}$, Merck Serono GmbH, Darmstadt, Germany) and trastuzumab (Herceptin ${ }^{\circledR}$, Genentech Inc., South San Francisco, CA, USA), which are monoclonal antibodies against ErbB1 and ErbB2, may be promising agents for the treatment of HNSCC (6). In addition, gefitinib (Iressa ${ }^{\circledR}$, AstraZeneca, London, UK), a monoclonal antibody that inhibits ErbB1-tyrosine kinase, 
has demonstrated anti-tumour activity in small cell lung and $\mathrm{HN}$ cancer $(2,7)$. Yoo et al (8) noticed that the aberrant expression of E-cadherin and $\beta$-catenin in non-small cell lung cancer harbouring EGFR mutations was associated with poor response to EGFR-tyrosine kinase inhibitor. Thus, the expression levels of E-cadherin and $\beta$-catenin may affect certain anti-tumour therapies (9).

Lapatinib, a novel synthetic small molecule inhibitor of EGF1 and human HER2-tyrosine kinases, is used in the form of lapatinib ditosylate (Tyverb ${ }^{\circledR}$, GlaxoSmithKline, Brentford, UK) as an active drug for breast and other solid tumours (2). In a randomized double-blind phase III trial with 67 patients, Harrington et al (10) demonstrated that lapatinib combined with CRT was a well-tolerated and safe therapy in patients with high risk of recurrence following surgical treatment for stage III/IV HN cancer. Thus, lapatinib may be used as concomitant and maintenance therapy during cisplatin-based CRT, since this drug was able to increase the rate of complete response at 6 months post-CRT in p16- $\mathrm{HNSCC}$ (10).

The metastatic process consists of several steps: i) The initial step, termed invasion, which requires the epithelial tumour cells to become motile and degrade the underlying basement membrane; ii) the second step, known as intravasation, during which tumour cells invade across the endothelial lamina prior to penetrating into blood or lymphatic vessels; iii) the third step, known as systemic transport, during which a small number of tumour cells appear to be capable of surviving various insults within circulation; iv) the fourth step, termed extravasation, during which a number of surviving cells may arrest in the vascular lumen; and v) the final step, named colonization, which represents the potential of the surviving tumour cells to proliferate (11).

Epithelial-mesenchymal transition (EMT) is described as the loss of cell adhesion of non-motile, polarized epithelial cells, followed by their transformation into a fibroblastoid, mesenchymal phenotype with a high ability to migrate (12). EMT has been suggested to be crucial for the development of a metastatic carcinoma cell phenotype with potential capacity of invasion(12). In oral SCC, EMT is characterized by the downregulation of epithelial-specific adhesion proteins such as tight and adherent junction proteins, including E-cadherin, cytokeratin, claudin and desmoplakin (13). Furthermore, EMT induces the expression of mesenchymal proteins such as vimentin, $\mathrm{N}$-cadherin and fibronectin, and promotes the development of migratory attributes and alterations in the morphology of the cells, including cell scattering (13-15). Matrix metalloproteinases (MMPs) such as MMP-3 and -9 act as EMT regulators by controlling certain aspects of oncogenesis (16). It has been previously reported that the selective blockade of MMP-14 appears to abrogate invasion, tumour growth and angiogenesis in ovarian cancer cells (17). By contrast, Zarrabi et al (18) have reported that the inhibition of MMP-14 promotes the migration of cancer cells (18). The role of c-kit during EMT remains unclear. Also known as cluster of differentiation (CD)117, c-kit is a member of the receptor tyrosine kinase family, and acts as oncogene in several tumours (19). Tang et al (20) have previously described an important function for c-kit in the progression of salivary adenoid cystic cancer by orchestrating EMT. In addition, the authors observed that the overexpression of c-kit correlated with poor prognosis in these patients.
Various growth factors are capable of inducing EMT, including vascular endothelial growth factor, hepatocyte growth factor, transforming growth factor $\beta 1$ (TGF $\beta 1$ ) and EGF (16,21-24). Epithelial cells may activate a transitory EMT program and its reverse process, known as mesenchymal-epithelial transition (MET), in order to continue their differentiation (12). These dynamic EMT/MET events highlight the remarkable flexibility exhibited by differentiated cells during morphogenesis and carcinogenesis $(11,25)$. Brabletz et al (26)observed an association between nuclear $\beta$-catenin and mesenchymal transition in metastases, as strong expression of nuclear $\beta$-catenin was detected in the central areas of many metastases; however, tumor cells recapitulated the differentiated epithelial phenotype of the primary tumor. This indicates an ongoing shift between EMT and MET during tumor progression.

MET is characterized by a reduction of proliferative activity in the destroying tumour cells, which express high levels of nuclear $\beta$-catenin (27). Lee et al (16) reported the findings of previous studies, which had identified hybrid cells exhibiting epithelial and mesenchymal phenotype. This metastable phenotype was characterized by residual expression of cadherin, cytokeratin, nuclear $\beta$-catenin and vimentin, in addition to collective cell growth.

Previous studies have suggested that the multifunctional protein $\beta$-catenin is one of the most important factors for reducing cell-cell interactions in malignant epithelial cells $(28,29)$. However, previous studies have reported that $\beta$-catenin participates in the development of $\mathrm{HN}$ cancer via a nuclear downstream effector of the canonical wingless-related integration site (WNT)-signalling cascade (15). Membrane-associated $\beta$-catenin may be released into the cytoplasm by alteration of the degradation complex, destabilization of cell-cell adhesion and loss of expression of E-cadherin (12). The accumulation of $\beta$-catenin in the cytoplasm leads to its nuclear translocation, whereby it acts as cofactor of transcriptional regulators. In invasive regions, tumour cells undergoing EMT dissociate into single, disseminating tumour cells, which exhibit a marked accumulation of nuclear $\beta$-catenin. The process of nuclear accumulation of $\beta$-catenin and subsequent EMT is reversed in metastases, while tumour cells adopt the differentiated epithelial phenotype (12). This indicates continuous switching between EMT and MET during the formation of metastases (26). During the periods of reduced proliferative activity, high expression levels of nuclear $\beta$-catenin have been observed in dissociating mesenchymal tumour cells (30). However, the regulators of the intracellular distribution of $\beta$-catenin, which are responsible for the heterogeneous pattern of expression of $\beta$-catenin observed in tumour cells, remain unknown (31).

Cells undergoing EMT become invasive and develop resistance to anticancer agents (32). The acquisition of EMT features has also been associated with chemoresistance following standard chemotherapy (33). Furthermore, EMT has been suggested to be associated with drug resistance to gefitinib and erlotinib (Tarceva ${ }^{\circledR}$, OSI Pharmaceuticals, Inc., Melville, NY, USA) in non-small cell lung cancer (32). However, in pancreatic and ovarian cancer, stable cell lines resistant to gemcitabine $\left(\right.$ Gemzar $^{\circledR}$, Eli Lilly, Indianapolis, IN, USA) and paclitaxel $\left(\right.$ Taxol $^{\circledR}$, Bristol-Myers Squibb, New York 
City, NY, USA), which were established by continuous exposure to these drugs, were able to undergo EMT with increased expression levels of snail family zinc finger 1 and twist family bHLH transcription factor 1, which are transcription factors that regulate the EMT process $(34,35)$.

Therefore, the identification of tumour cell phenotypes with malignant potential is of clinical interest, since in order to inhibit the process of EMT or EMT-associated resistance to anticancer agents, it is necessary to examine the phenotype of SCC cells. The aim of the present study was to assess in a quantitative and qualitative manner the expression pattern of vimentin, $\beta$-catenin, E-cadherin, MMP-14 and c-kit in mesenchymal- and epithelial-associated SCC cells, prior and following exposure to lapatinib and gefitinib, and to evaluate the invasive metastatic cell phenotype by detecting potential differences between mesenchymal' ${ }^{-}$and epithelial ${ }^{-}$SCC cells.

\section{Materials and methods}

Cell lines and culture. The SCC cell lines HNSCC22B (UMSCC22B) and HNSCC11A (UMSCC11A), which descend from human metastatic HNSCC of the sinus piriformis (hypopharynx) and supraglottic larynx, were kindly provided by Dr T. E. Carey (University of Michigan, Ann Arbor, MI, USA). Cells were cultured at $37^{\circ} \mathrm{C}$ in humidified atmosphere with $5 \% \mathrm{CO}_{2}$, using $500 \mathrm{ml}$ minimum essential medium (Gibco; Thermo Fisher Scientific, Inc., Waltham, MA, USA) supplemented with $10 \%$ fetal bovine serum (FBS; Thermo Fisher Scientific, Inc.) and antibiotics (5 ml L-glutamine solution, cat no. 9183.1; Carl Roth GmbH \& Co. KG, Karlsruhe, Germany; and penicillin, streptomycin, fungizone solution, cat no. C42020; PromoCell $\mathrm{GmbH}$, Heidelberg, Germany). For immunocytochemistry, $1 \times 10^{4}$ cells/well were seeded in 8 -well cell culture slides (BD Biosciences, Franklin Lakes, NJ, USA). When confluent, cells were starved using minimum essential medium (MEM) depleted of FBS for $5 \mathrm{~h}$, and then incubated for 5, 24 and $96 \mathrm{~h}$ with 0.5 and $2 \mu \mathrm{g} / \mathrm{ml}$ lapatinib and gefitinib in $0.5 \%$ FBS/MEM. The stimulation was repeated every $24 \mathrm{~h}$. The different drug concentrations and stimulation times used in the present study were selected upon performing a cell proliferation assay with alamarBlue ${ }^{\circledR}$ (AbD Serotec, Oxford, UK). Following incubation with the above drugs, the cell supernatants were collected together in sterile tubes, and stored at $-20^{\circ} \mathrm{C}$ until further analysis.

Enzyme-linked immunosorbent assay (ELISA). The protein expression levels of $\beta$-catenin, E-cadherin and vimentin were determined by ELISA, using DuoSet ${ }^{\circledR}$ IC ELISA (R\&D Systems, Inc., Minneapolis, MN, USA) and PathScan ${ }^{\circledR}$ Total Vimentin Sandwich ELISA Kit (cat no. 7789; R\&D Systems, Inc.), respectively. The system utilized anti-human solid-phase monoclonal antibodies and enzyme-linked monoclonal mouse antibodies against $\beta$-catenin (Human Total $\beta$-Catenin DuoSet ${ }^{\circledR}$ IC ELISA, 2 Plate; cat no. DYC1329; R\&D Systems, Inc.) and E-cadherin (Human E-Cadherin DuoSet ${ }^{\circledR}$ ELISA, 15 Plate; cat no. DY648; R\&D Systems, Inc.) and a mouse monoclonal antibody against vimentin (PathScan ${ }^{\circledR}$ Total Vimentin Sandwich ELISA Kit; cat no. 7789; Cell Signaling Technology Inc, Danvers, MA, USA). Following 0,
5, 24 and 96-h incubation with $2 \mu \mathrm{g} / \mathrm{ml}$ lapatinib and gefitinib, the expression levels of $\beta$-catenin, E-cadherin and vimentin in the supernatants of the treated and untreated cells were determined by measuring the optical density at a wavelength of $540 \mathrm{~nm}$ in a microplate reader. Each assay was measured in $100 \mu \mathrm{l}$ of supernatant, and all analyses and calibrations were performed in triplicate. The concentration of $\beta$-catenin and E-cadherin, reported in $\mathrm{pg} / \mathrm{ml}$, and vimentin, reported in $\mu \mathrm{g} / \mathrm{ml}$, were defined upon subjecting the HNSCC tumour cell lines to a quantitative cell proliferation assay with alamarBlue ${ }^{\circledR}$ (AbD Serotec). The non-stimulated cells were grow to confluence in the presence of $10 \% \mathrm{FBS} / \mathrm{MEM}$ and then incubated for $5 \mathrm{~h}$ with MEM and phosphate-buffered saline (PBS; Dako, Glostrup, Germany) instead of drug.

Immunocytochemistry. Immunocytochemical analysis was performed using anti-human antibodies directed against $\beta$-catenin (monoclonal rabbit; 1:200 dilution; cat no. 32572; Abcam, Cambridge, UK), E-cadherin (monoclonal mouse; 1:50 dilution; cat no. Ab1416; Abcam), c-kit (polyclonal rabbit; 1:200 dilution; cat no. NB100-1766; Novus Biologicals, LLC; Littleton, CO, USA), MMP-14 (polyclonal rabbit; 1:250 dilution; cat no. 73879; Abcam) and vimentin (monoclonal mouse; 1:50 dilution; cat no. M0725; Dako). Immunostaining was performed using the streptavidin-biotin complex method (Amersham, RPN 1051; 1:100 dilution). Prior to being subjected to immunocytochemistry, SCC cells were cultured in 8-well chambers overnight, and exposed to different concentrations of lapatinib $(0.5$ or $2 \mathrm{mg} / \mathrm{ml})$ for $0,5,24$ and $96 \mathrm{~h}$ while growing to confluency. Subsequently, the cells underwent fixation with a 2:1 dilution of acetone (cat no. 100014.2511; Merck Serono, $\mathrm{GmbH}$ ) and alcohol (denaturedethanol absolute, 99,8\%; cat no. K928.4; Carl Roth GmbH \& Co. KG), followed by three washes with PBS (Buffer kit; Dako) for 5 min each time at room temperature.

Next, the cells were automatically stained with TechMate $^{\mathrm{TM}} 500$ (Dako), which executed the following steps: i) Incubation of the cells for $30 \mathrm{~min}$ at room temperature with the corresponding primary antibody solution, using the aforementioned ratios of antibody:cells; and ii) three washes of the slices with PBS for $5 \mathrm{~min}$ at room temperature. Following incubation with a mouse antibody against alkaline phosphatase-anti-alkaline phosphatase (cat no. K5000; Dako), the results of the immunoreaction were visualized with DAKO ChemMate ${ }^{\mathrm{TM}}$ Detection Kit (Dako) and AxioVision Scan Scope 4.8.3 software (Zeiss AG, Oberkochen, Germany), according to the manufacturers' protocol. For this purpose, the cells were incubated in sheep serum (1:10 dilution; cat no. ADI-ALBSH20-S; Linaris Biological Products GmbH, Dossenheim, Germany) in the presence of the aforementioned monoclonal antibodies. Next, the cells were incubated with a specific biotinylated secondary antibody and streptavidin-biotin horseradish peroxidase complex (GE Healthcare Life Sciences, Chalfont, UK) for $45 \mathrm{~min}$ at room temperature. Aminoethylcarbazol (cat no. A5754; Sigma-Aldrich, St. Louis, MO, USA) was used as chromogen in the peroxidase reaction, and the endogenous peroxidase activity was blocked prior to washing the cells three times with PBS for $5 \mathrm{~min}$ each at room temperature. For the negative controls, the cells were incubated with all the reagents 
described above, except for the primary antibody. The sections underwent counterstaining by Harris haematoxylin (MSDS code, SSHXHHE; Emergo Group, The Hague, The Netherlands) for $30 \mathrm{sec}$, followed by dehydration in graded ethanol and coverslipping. The protein expression levels of $\beta$-catenin, E-cadherin, vimentin, MMP-14 and c-kit were determined immunohistochemically using an AxioVision Scan Scope microscope (Zeiss AG) and AxioVision Scan Scope 4.8.2 software (Zeiss AG). The staining intensity was considered to be strong if $>80 \%$ cells were positively stained; moderate, if $50-80 \%$ cells were positively stained; and negative, if no positively stained cells were detected.

Statistical analysis. Statistical analysis was performed in collaboration with Dr C. Weiss (Institute of Biomathematics, Faculty of Medicine, Mannheim, Germany). Data are presented as the mean \pm standard deviation. $\mathrm{P}<0.05$ was considered to indicate a statistically significant difference. Any differences in the protein expression levels of $\beta$-catenin, E-cadherin, vimentin, MMP-14 and c-kit between the treated and control cultures were analysed using Dunnett's and t tests for linear models.

\section{Results}

Immunocytochemistry of E-cadherin, vimentin, $\beta$-catenin, MMP-14 and c-kit expression in HNSCC11A and HNSCC22B cells. Prior to stimulation, the established HNSCC11A and HNSCC22B cell lines were assessed for morphological alterations and expression of key EMT markers. The SCC cell line HNSCC22B (UMSCC22B) exhibited the most pronounced epithelial phenotype (scattering-, E-cadherin ${ }^{+}$and vimentin ${ }^{-}$) (data not shown). Contrarily, the HNSCC11A SCC cell line (UMSCC11A) exhibited the most pronounced mesenchymal phenotype (scattering ${ }^{+}$, E-cadherin ${ }^{-}$and vimentin ${ }^{+}$), with disaggregated cell growth and spindle shape (data not shown). Immunocytochemical analysis demonstrated that in the negative controls of the HNSCC11A cell line, the cells expressed a moderate level of membrane-associated E-cadherin and a strong positivity for vimentin. However, no deposition of c-kit and MMP-14 was observed (Fig. 1). In the lapatinib-treated HNSCC11A cells, an increase in the levels of membrane-associated E-cadherin and a considerable loss of deposition of vimentin was observed, particularly at $24 \mathrm{~h}$ post-incubation (Fig. 1). Lapatinib also induced a reduction in the levels of $\beta$-catenin and the reorganization of membrane-associated $\beta$-catenin and its nuclear deposition in the HNSCC11A cell line, particularly following $24 \mathrm{~h}$ incubation with lapatinib. This implies that the effect of lapatinib on the expression of $\beta$-catenin may be reversible. At $96 \mathrm{~h}$ post-incubation, a stronger expression of $\beta$-catenin was observed, whereas no deposition of MMP-14 and c-kit in the HNSCC11A cells was detected following treatment with lapatinib (Fig. 1).

By contrast, the non-treated HNSCC22B cells preferentially exhibited a strong membranous staining for E-cadherin and $\beta$-catenin, but no immunohistochemical positivity for vimentin and c-kit (Table I). Following incubation with lapatinib, a slightly reduced deposition of E-cadherin and a mild increase in the expression levels of $\beta$-catenin were noticed, particularly at $96 \mathrm{~h}$ post-incubation, but no positivity for vimentin and c-kit was observed. In addition, no increase in immunohistochemical positivity for MMP-14 was detected at post-incubation with lapatinib compared with the control (Table I). The differences observed for control cells at different times may be due to epigenetic mechanisms that activate plasticity (36), thus affecting cell phenotype (Table I).

ELISA of total protein expression in HNSCC11A and HNSCC22B cells. In order to determine the total protein expression levels in the supernatant of the tumour cell lines HNSCC22B and HNSCC11A, ELISA analyses were conducted at 5, 24 and $96 \mathrm{~h}$ post-incubation with $2 \mu \mathrm{g} / \mathrm{ml}$ lapatinib and gefitinib. The total protein content appeared to increase with time in the control and drug-treated cells, suggesting that none of the drugs tested have a clear effect on total protein expression levels. By contrast, an increase in total protein expression levels was detected in HNSCC22B cells, particularly at $96 \mathrm{~h}$ post-stimulation with lapatinib. In HNSCC11A cells, the total protein expression levels were markedly downregulated following treatment with $2 \mu \mathrm{g} / \mathrm{ml}$ gefitinib, particularly at 5 and $96 \mathrm{~h}$ post-incubation (total protein content $=19.38$ and $423.06 \mu \mathrm{g} / \mathrm{ml}, \mathrm{P}=0.0089$ and 0.0038 , respectively), compared with the control group (Fig. 2). The concentration of the drug did not exert a significant influence on the total protein expression levels (data not shown).

ELISA of E-cadherin, vimentin and $\beta$-catenin expression in HNSCC11A and HNSCC22B cells. In contrast to the HNSCC11A cells in the control group, high protein expression levels of E-cadherin were exhibited by the non-stimulated HNSCC22B cells at $5 \mathrm{~h}$ incubation (69.919 vs. $227.520 \mathrm{pg} / \mathrm{ml}$, respectively). The increase in the levels of E-cadherin displayed by these two SCC cell lines upon incubation with lapatinib was time-dependent. A significant increase in the expression levels of E-cadherin was detected in HNSCC22B cells following 96-h treatment with $2 \mu \mathrm{g} / \mathrm{ml}$ lapatinib $(7,814.760 \mathrm{pg} / \mathrm{ml}, \mathrm{P}<0.0001)$ and $5-\mathrm{h}$ incubation with $2 \mu \mathrm{g} / \mathrm{ml}$ gefitinib $(118.700 \mathrm{pg} / \mathrm{ml}, \mathrm{P}<0.0001)$ (Table II). Notably, in the SCC HNSCC22B cell line, a marginal increase in the expression level of E-cadherin was noted following a prolonged treatment time (96 h) with lapatinib (Fig. 3A and B, Table II). In Table II, the differences observed for control cells at different times may be due to epigenetic mechanisms that activate plasticity (36).

In contrast to the low protein expression levels of vimentin in HNSCC22B cells, higher protein expression levels were observed in control HNSCC11A cells at 5-h incubation $(0.247 \mu \mathrm{g} / \mathrm{ml})$. The protein expression levels of vimentin in HNSCC22B cells were reduced following 24-h incubation with lapatinib and gefitinib. The expression of vimentin was not significantly downregulated in HNSCC11A cells following 96-h treatment with lapatinib $(0.170 \mu \mathrm{g} / \mathrm{ml}, \mathrm{P}=0.5000)$, while upon $96-\mathrm{h}$ treatment with $2 \mu \mathrm{g} / \mathrm{ml}$ gefitinib, the protein expression levels of vimentin in these cells were $0.533 \mu \mathrm{g} / \mathrm{ml}$ $(\mathrm{P}=0.96)$. By contrast, increased protein expression levels of vimentin were observed in HNSCC22B cells following prolonged treatment with lapatinib and gefitinib, particularly upon 96 and 5-h incubation with these drugs (Fig. 3C and D).

In summary, low protein expression levels of vimentin were detected in non-stimulated HNSCC22B cells, and a 


\section{Lapatinib}

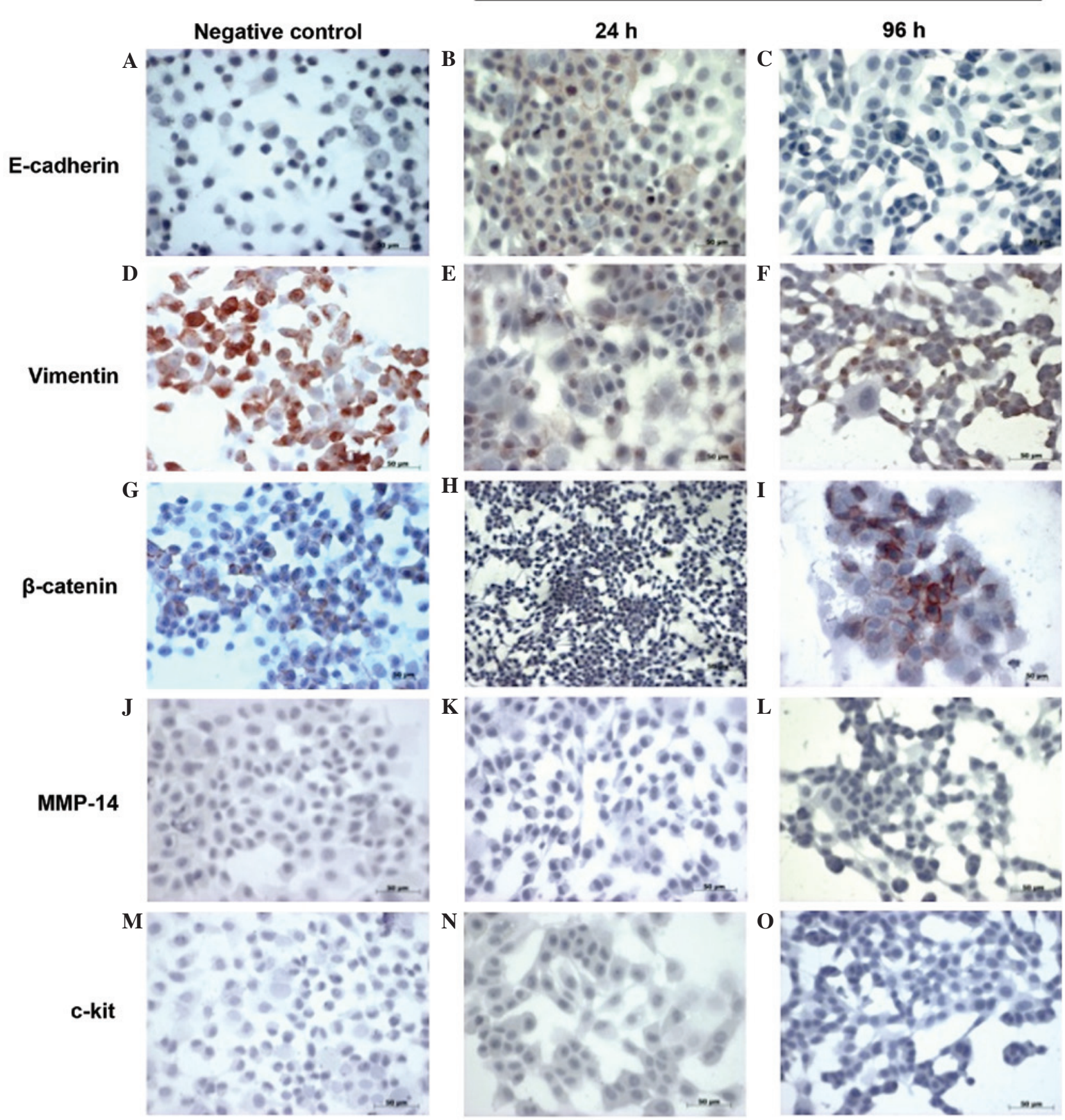

Figure 1. Immunohistochemical reactivity for (A-C) E-cadherin, (D-F) vimentin, (G-I) $\beta$-catenin, (J-L) MMP-14 and (M-O) c-kit in HNSCC11A cells, prior and subsequently to treatment with $0.5 \mu \mathrm{g} / \mathrm{ml}$ lapatinib for 24 and $96 \mathrm{~h}$. MMP, matrix metalloproteinase; HNSCC, head and neck squamous cell carcinoma.

time-dependent increase in the protein expression levels of vimentin was observed in HNSCC11A cells exposed to $2 \mu \mathrm{g} / \mathrm{ml}$ gefitinib for 5-96 $\mathrm{h}$, whereas the drug treatment at different concentrations did not exert a significant influence on the protein expression levels of vimentin (data not shown).

High protein expression levels of $\beta$-catenin were detected in the control HNSCC22B cells upon 5-h incubation $(7,587.00 \mathrm{pg} / \mathrm{ml})$. HNSCC22B cells displayed reduction in the protein expression levels of $\beta$-catenin following incubation with lapatinib and gefitinib. In HNSCC22B cells, the protein expression levels of $\beta$-catenin were significantly downregulated upon incubation with $2 \mu \mathrm{g} / \mathrm{ml}$ gefitinib for 5 and $24 \mathrm{~h}$ $(1,051.33$ and $960.33 \mathrm{pg} / \mathrm{ml}, \mathrm{P}=0.0021$ and 0.0293 , respectively). By contrast, HNSCC11A cells displayed a consistent trend towards an incubation time-dependent increase in the protein expression levels of $\beta$-catenin after $24 \mathrm{~h}$, and then stabilized in the control and treated cells. Particularly, a significant impact on the protein expression levels of $\beta$-catenin was observed in HNSCC11A cells following 96-h stimulation with $2 \mu \mathrm{g} / \mathrm{ml}$ gefitinib $(\mathrm{P}=0.0003)$. Significant downregulation of 
the expression of $\beta$-catenin was observed in HNSCC22B cells upon 5, 24 and 96-h incubation with $2 \mu \mathrm{g} / \mathrm{ml}$ gefitinib $(1,051.33$, 960.33 and $680.53 \mathrm{pg} / \mathrm{ml}, \mathrm{P}=0.0021,0.0293$ and 0.0183 , respectively; Fig. 3E and F, Table III). Similarly, a significant time-dependent reduction in the expression levels of $\beta$-catenin was observed in HNSCC22B cells when exposed to $0.5 \mu \mathrm{g} / \mathrm{ml}$ gefitinib for $5 \mathrm{~h}(3,496.00 \mathrm{pg} / \mathrm{ml}$; $\mathrm{P}<0.0400$; data not shown). The differences observed for control cells at different times in Table III may be due to epigenetic mechanisms that activate plasticity (36).

\section{Discussion}

Based on its incidence rate, HNSCC is considered the sixth most common type of cancer worldwide (37). The consumption of tobacco and alcohol have been identified as risk factors for HNSCC, and appear to exert a synergistic effect in the development of the disease (12). In addition, certain types of HNSCC, particularly oropharyngeal cancer, are caused by infection with high risk HPV (38). Patients with HNSCC usually exhibit poor survival rates, due to the high frequency of local invasion, cervical lymph node dissemination, distant metastasis and second primary tumours (39). In addition, HNSCC presents a high propensity to develop local recurrence following treatment (40). Concomitant CTR treatment has been previously demonstrated to increase the overall and five-year survival rate of patients with HNSCC at advanced stages, and offer better locoregional control rate (29). To further improve the survival rates for patients with HNSCC, particularly those presenting with unresectable HNSCC, innovative strategies and targeted therapies must be explored (41). HNSCC arises from the accumulation of epigenetic and genetic events at the cellular level, which result in malignant cells exhibiting characteristics such as resistance to apoptosis, insensitivity to anti-growth signals, abnormalities in cancer-associated signalling pathways, limitless replicative potential, self-sufficiency regarding growth signals, increased angiogenesis, metastasis and invasion capacity (40). Although the tumorigenic pathways and molecular aetiologies of HNSCC have been studied extensively, a limited number of diagnostic clinical applications are currently in practice (42).

Thus, to improve the survival rates of patients with HNSCC, it is important to investigate the phenotypic alterations that occur in HNSCC cells and enable them to destroy the basement membrane, invade and metastasize (12). In the past years, there has been an increased interest in EMT and its role in the progression of HNSCC (39). EMT is a mechanism by which solid tumours gain metastatic potential (43). During EMT, cells within the tumour environment downregulate the expression of adhesion receptors such as cadherins and integrins, which are involved in cell-cell attachment. By contrast, the expression of adhesion receptors that induce cell motility is upregulated during EMT (44). In addition, the expression of metalloproteases is also upregulated during EMT, which promotes metastasis (45). Therefore, the identification of the phenotype responsible for the malignant potential of SCC tumour cells is of clinical interest (46). Richter et al (47) previously demonstrated that oral SCC cells with an epithelial phenotype were capable of undergoing a complete EMT process, including downregulation of E-cadherin, upregulation of vimentin and scattered cell growth,
Table I. Immunostaining results for E-cadherin, vimentin, $\beta$-catenin, MMP-14 and c-kit expression in HNSCC22B cells.

\begin{tabular}{lccc}
\hline & \multicolumn{3}{c}{ Lapatinib } \\
\cline { 2 - 4 } Immunostaining & $5 \mathrm{~h}$ & $24 \mathrm{~h}$ & $96 \mathrm{~h}$ \\
\hline Control group & & & \\
E-cadherin & ++ & ++ & + \\
Vimentin & 0 & 0 & 0 \\
$\beta$-catenin & + & $+/++$ & + \\
MMP-14 & 0 & $0 /+$ & $0 /+$ \\
c-kit & 0 & 0 & 0 \\
Lapatinib $0.5 \mu \mathrm{g}$ & & & \\
E-cadherin & ++ & ++ & $+/++$ \\
Vimentin & 0 & 0 & 0 \\
$\beta$-catenin & ++ & ++ & ++ \\
MMP-14 & 0 & $0 /+$ & 0 \\
c-kit & 0 & 0 & 0 \\
Lapatinib 2 $\mu \mathrm{g}$ & & & \\
E-cadherin & ++ & ++ & ++ \\
Vimentin & 0 & 0 & 0 \\
$\beta$-catenin & ++ & + & ++ \\
MMP-14 & 0 & 0 & 0 \\
c-kit & 0 & 0 & 0 \\
\hline
\end{tabular}

0 , negative immunostaining; + , weak immunostaining; ++ , moderate immunostaining; +++, strong immunostaining; MMP, matrix metalloproteinase; HNSCC, head and neck squamous cell carcinoma.

following prolonged co-stimulation with EGF and TGF $\beta 1$. EMT is a key developmental program that is often activated during cancer progression and may promote resistance to anti-tumour therapy. Thus, the inhibition of EMT appears to be the crucial mechanism to avoid drug resistance (33). Lee et al (16) assessed the morphological alterations displayed by lung and colon cancer cells resistant to gefitinib chemotherapy, and evaluated their cell invasion and motility abilities, and the levels of key EMT markers expressed by these cells. The authors demonstrated that the transfection of microRNA-147, aimed to induce MET and promote cell cycle arrest, increased the sensitivity of these tumour cells towards the EGFR inhibitor gefitinib (48).

$\beta$-catenin is involved in WNT-signalling (44). Upon nuclear translocation, $\beta$-catenin may upregulate the transcription genes that promote cytoplasmatic degradation and cancer progression, thus affecting the progression of EMT (49). Brabletz et al (27) detected nuclear accumulation of $\beta$-catenin in dedifferentiated mesenchymal-like tumour cells during the invasion step of colorectal adenocarcinoma. The metastatic process of epithelial tumours is characterised by aberrant expression of E-cadherin and $\beta$-catenin, which occurs at different points in time (46).

Significant downregulation of the expression of $\beta$-catenin was observed in HNSCC22B cells following incubation with gefitinib for 5 and $24 \mathrm{~h}$. In HNSCC11A cells, nuclear deposition of $\beta$-catenin was detected by histopathological reactivity, particularly following 96-h incubation with lapatinib. These 
A Protein expression in HNSCC22B cells

흥 $\square$ Negative control Gefitinib వ Lapatinib

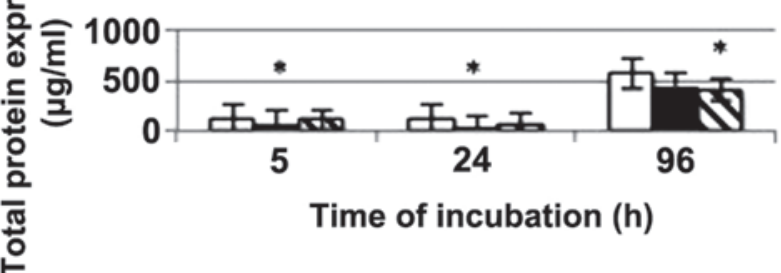
Protein expression in HNSCC11A cells

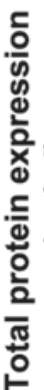

Figure 2. Total protein expression levels in (A) HNSCC22B and (B) HNSCC11A cells following incubation with $2 \mu \mathrm{g} / \mathrm{ml}$ gefitinib and lapatinib for 5, 24 and $96 \mathrm{~h}$. Data are presented as the mean \pm standard deviation. ${ }^{\mathrm{P}}<0.05$. HNSCC, head and neck squamous cell carcinoma.

Table II. Expression levels of E-cadherin in HNSCC11A and HNSCC22B cells following incubation with $2 \mu \mathrm{g} / \mathrm{ml}$ lapatinib and gefitinib, as determined by enzyme-linked immunosorbent assay.

\begin{tabular}{lccr}
\hline & \multicolumn{3}{c}{ Mean \pm SD expression levels of E-cadherin, pg/ml (P-value $)^{\mathrm{a}}$} \\
\cline { 2 - 4 } Incubation time (h) & Control & Lapatinib & Gefitinib \\
\hline HNSCC11A & & & \\
5 & $69.919 \pm 9.89$ & $74.601 \pm 4.46(0.9791)$ & $105.395 \pm 10.98(0.0197)^{\mathrm{b}}$ \\
24 & $858.025 \pm 184.42$ & $324.370 \pm 186.53(<0.0001)^{\mathrm{b}}$ & $96.557 \pm 10.89(<0.0001)^{\mathrm{b}}$ \\
96 & $8,676.943 \pm 367.50$ & $8,250.640 \pm 1,007.40(0.9684)$ & $6,073.640 \pm 1,700.32(0.0355)$ \\
HNSCC22B & & & \\
5 & $227.520 \pm 19.08$ & $220.920 \pm 25.09(0.9594)$ & $118.700 \pm 17.79(<0.0001)^{\mathrm{b}}$ \\
24 & $2,109.010 \pm 454.91$ & $1,233.480 \pm 1,041.00(0.5330)$ & $1,538.070 \pm 1,196.82(0.8194)$ \\
96 & $6,053.370 \pm 323.68$ & $7,814.760 \pm 249.48(<0.0001)^{\mathrm{b}}$ & $5,260.540 \pm 436.67(0.0111)^{\mathrm{b}}$
\end{tabular}

${ }^{\text {a }} \mathrm{P}$-value vs. negative control (Dunnett's test, $\mathrm{n}=3$ ); ${ }^{\mathbf{b}}$ statistically significant differences were observed upon treatment with lapatinib and, in particular, gefitinib. HNSCC, head and neck squamous cell carcinoma; SD, standard deviation.

Table III. Expression levels of $\beta$-catenin in HNSCC11A and HNSCC22B cells following incubation with $2 \mu \mathrm{g} / \mathrm{ml}$ lapatinib and gefitinib, as determined by enzyme-linked immunosorbent assay.

\begin{tabular}{|c|c|c|c|}
\hline \multirow[b]{2}{*}{ Incubation time $(\mathrm{h})$} & \multicolumn{3}{|c|}{ Mean \pm SD expression levels of $\beta$-catenin, $\mathrm{pg} / \mathrm{ml}(\mathrm{P} \text {-value })^{\mathrm{a}}$} \\
\hline & Control & Lapatinib & Gefitinib \\
\hline \multicolumn{4}{|l|}{ HNSCC11A } \\
\hline 5 & $6,316.33 \pm 2.697 .22$ & $5,008.33 \pm 3,464.97(0.9288)$ & $1,262.67 \pm 433.66(0.1231)$ \\
\hline 24 & $10,557.33 \pm 2,958.91$ & $12,331.00 \pm 1,327.30(0.8905)$ & $7,759.67 \pm 4,585.48(0.6567)$ \\
\hline 96 & $10,774.33 \pm 731.52$ & $9,692.33 \pm 277.49(0.1350)$ & $7,774.33 \pm 778.50(0.0003)$ \\
\hline \multicolumn{4}{|l|}{ HNSCC22B } \\
\hline 5 & $7,587.00 \pm 1,848.14$ & $6,308.67 \pm 1,830.21(0.7439)$ & $1,051.33 \pm 141.93(0.0021)^{\mathrm{b}}$ \\
\hline 24 & $7,546.00 \pm 1,653.26$ & $4,009.67 \pm 3,565.12(0.3053)$ & $960.33 \pm 140.86(0.0293)^{\mathrm{b}}$ \\
\hline 96 & $55.07 \pm 52.2$ & $251.83 \pm 86.62(0.6529)$ & $680.53 \pm 133.54(0.0183)^{\mathrm{b}}$ \\
\hline
\end{tabular}

${ }^{a} \mathrm{P}$-value vs. negative control (Dunnett's test, $\mathrm{n}=3$ ); ${ }^{\mathbf{b}}$ statistically significant differences were observed in HNSCC22B cells upon treatment with gefitinib, at 5, 24 and $96 \mathrm{~h}$ post-incubation. HNSCC, head and neck squamous cell carcinoma; SD, standard deviation.

results are in agreement with the aforementioned findings by Brabletz et al (27), who had described an increase in the levels of nuclear $\beta$-catenin in dedifferentiated mesenchymal-like tumour cells at the invasive front in colorectal cancer. 

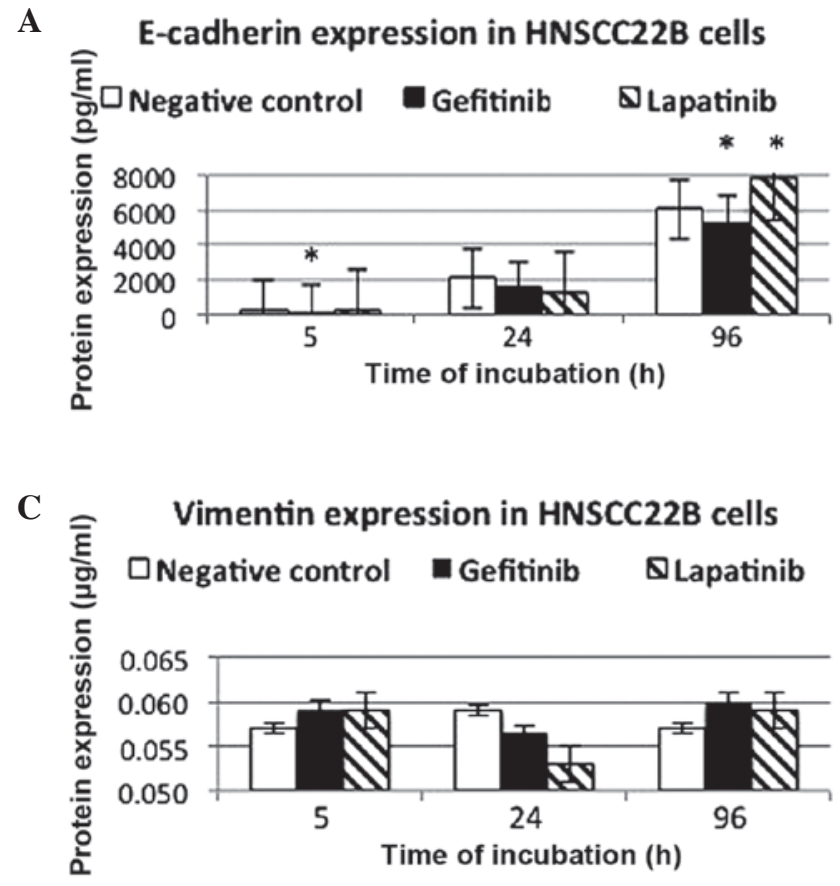

E

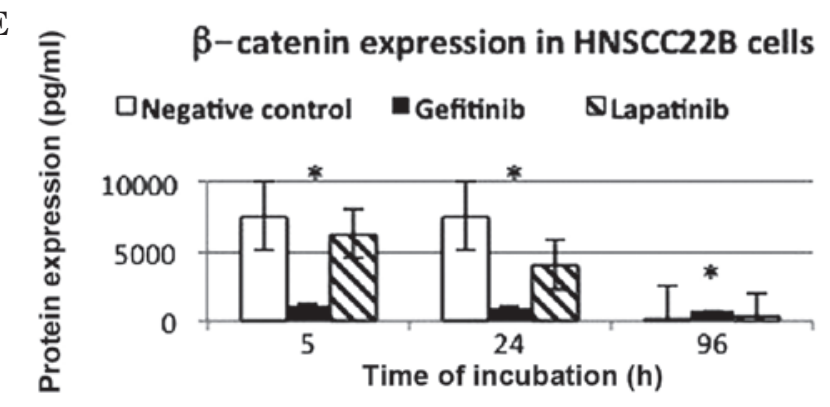

\section{B}

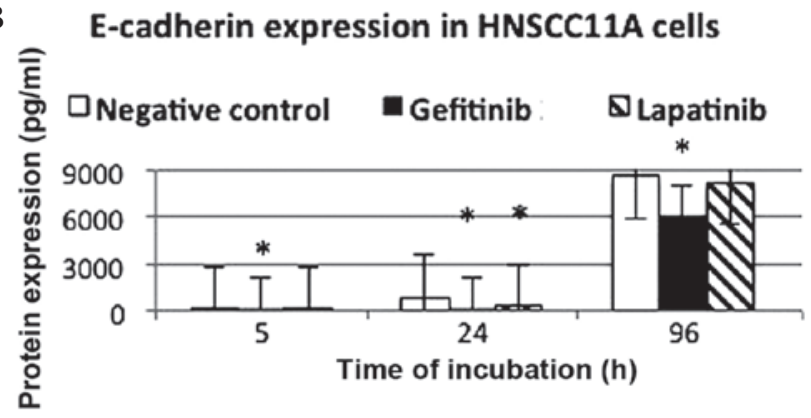

D

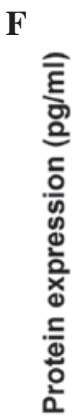

Figure 3. Protein expression levels of E-cadherin in (A) HNSCC22B and (B) HNSCC11A cells, vimentin in (C) HNSCC22B and (D) HNSCC11A cells and $\beta$-catenin in (E) HNSCC22B and (F) HNSCC11A cells, following incubation with $2 \mu \mathrm{g} / \mathrm{ml}$ gefitinib for 5, 24 and $96 \mathrm{~h}$. Data are presented as mean+/- standard deviation. ${ }^{*} \mathrm{P}<0.05$. HNSCC, head and neck cell carcinoma.

The majority of HNSCCs (>90\%) display overexpression of EGFR at the protein level (50), which is associated with local or regional recurrence and overall reduced survival $(51,52)$. Lapatinib is a novel synthetic small molecule inhibitor of EGFR and HER2 tyrosine kinases (53). In the present study, positivity for vimentin was detected immunocytochemically in non-stimulated HNSCC11A cells. Following incubation with lapatinib, reduced deposition of vimentin was observed in these cells. In addition, increased levels of E-cadherin were observed in HNSCC11A cells following 24-h incubation with lapatinib.

Housman et al (45) previously reported several factors occurring during EMT that participate in the development of drug resistance. These factors are dependent on the metastatic grade of the tumour, which is defined as the level of dedifferentiation and degree of EMT exhibited by the tumour (45). The reverse process of EMT, known as MET, has also been reported (54). EMT and MET are involved in organ development, stem cell biology, wound healing and cancer progression (44). In order to undergo MET, upregulation of E-cadherin is required, since this protein enables cells to return to their epithelial phenotype (43).
MET is characterized by the loss of mesenchymal markers, including vimentin, fibronectin and $\alpha$ smooth muscle protein, and the enhancement of epithelial markers such as E-cadherin, occludin and desmoplakin (54). In the present study, a mild upregulation of the expression levels of E-cadherin, and downregulation of the expression of vimentin, were observed in HNSCC11A cells following 96-h incubation with lapatinib. The same effect on expression of E-cadherin was also observed in the untreated HNSCC11A cells (Fig. 3D). These results suggest that the incubation with lapatinib inhibited a partial EMT and promoted a partial MET in these cells. Previous studies have indicated that MET may be enhanced by blocking the activity of certain factors and signalling pathways that activate EMT (55). Thus, metastatic cells may revert back via MET to re-acquire epithelial characteristics similar to exhibited by the cells in the primary tumour (44).

The different effects of gefitinib and lapatinib on the expression levels of $\beta$-catenin and vimentin may be explained by the different phenotypes of the HNSCC cell lines. The HNSCC22B cell line exhibited the most pronounced epithelial phenotype (scattering-,E-cadherin ${ }^{+}$and vimentin ${ }^{-}$. By contrast, 
the HNSCC11A cell line exhibited the most pronounced mesenchymal phenotype (scattering ${ }^{+}$, E-cadherin', vimentin ${ }^{+}$). Only oral SCC cells with an epithelial phenotype were capable of undergoing a complete EMT. This may also explain why different tumor cells show different changes following incubation with gefitinib and lapatinib. Furthermore, this suggests that inhibiting EMT by gefitinib or lapatinib cannot be observed in every tumor cell. Therefore, it is important to characterize the phenotype of the tumor cell line prior to treating with geftinib or lapatinib.

It has been previously demonstrated that the activation of EMT promotes local tumour invasion, intravasation and extravasation of the systemic circulation, while MET is essential for establishing macrometastases (25). Therefore, targeting EMT and MET may provide effective therapeutic agents for the treatment of cancer (25). EMT is associated with reduced cell proliferation, in contrast to MET, which promotes metastatic growth. Whether inhibiting EMT is a valid approach to prevent metastasis remains unknown. Nevertheless, potential therapeutic interventions aimed to target EMT and MET may be complex, since EMT occurs at an early stage of metastasis, whereas MET occurs at later stages (25). In the present study, aberrant expression levels of $\beta$-catenin were detected in HNSCC11A and HNSCC22B cells. Furthermore, the expression of vimentin was observed to be upregulated in HNSCC22B cells following incubation with lapatinib and gefitinib for $96 \mathrm{~h}$.

In order to develop novel anti-HNSCC therapies that block the progression of EMT, the mechanistic role of EMT markers associated with cell-cell contact in HNSCC cells should be further clarified. For this purpose, the cells in the present study were grown to confluency prior to stimulation. In HNSCC11A, vimentin-upregulated and small E-cadherin-downregulated SCC cells, MET was observed, alongside upregulated expression of $\beta$-catenin, particularly following 24-h treatment with lapatinib. Targeting EMT and MET may provide effective therapeutics for cancer. Thus, future studies on the molecular interactions associated with the inhibition of EMT and activation of MET are required, to further understand the process of drug-induced EMT and resistance of SCC cells to targeted therapy, and to develop novel anti-tumour therapies for the treatment of SCC.

\section{Acknowledgements}

The authors would like to thank Miss Petra Prohaska for her excellent technical assistance, and Dr C. Weiss for his valuable assistance in statistical analysis.

\section{References}

1. Denaro N, Russi EG, Adamo V and Merlano MC: State-of-the-art and emerging treatment options in the management of head and neck cancer: News from 2013. Oncology 86: 212-229, 2014.

2. Burris HA III: Dual kinase inhibition in the treatment of breast cancer: Initial experience with the EGFR/ErbB-2 inhibitor lapatinib. Oncologist 9 (Suppl 3): 10-15, 2004.

3. Kalyankrishna S and Grandis JR: Epidermal growth factor receptor biology in head and neck cancer. J Clin Oncol 24: 2666-2672, 2006.

4. Jedlinski A, Ansell A, Johansson AC and Roberg K: EGFR status and EGFR ligand expression influence the treatment response of head and neck cancer cell lines. J Oral Pathol Med 42: 26-36, 2013
5. Califano R, Morgillo F, De Mello RA and Mountzios G: Role of mesenchymal-epithelial transition amplification in resistance to anti-epidermal growth factor receptor agents. Ann Transl Med 3: $81,2015$.

6. Privitera G, Luca T, Musso N, Vancheri C, Crimi N, Barresi V, Condorelli $\mathrm{D}$ and Castorina $\mathrm{S}$ : In vitro antiproliferative effect of trastuzumab $\left(\right.$ Herceptin $^{\circledR}$ ) combined with cetuximab (Erbitux $\left.{ }^{\circledR}\right)$ in a model of human non-small cell lung cancer expressing EGFR and HER2. Clin Exp Med: Feb 26, 2015 (Epub ahead of print).

7. Erjala K, Sundvall M, Junttila TT, Zhang N, Savisalo M, Mali P, Kulmala J, Pulkkinen J, Grenman R and Elenius K: Signalling via ErbB2 and ErbB3 associates with resistance and epidermal growth factor receptor (EGFR) amplification with sensitivity to EGFR inhibitor gefitinib in head and neck squamous cell carcinoma cells. Clin Cancer Res 12: 4103-4111, 2006.

8. Yoo SB, Kim YJ, Kim H, Jin Y, Sun PL, Jheon S, Lee JS and Chung JH: Alteration of the E-cadherin/ $\beta$-catenin complex predicts poor response to epidermal growth factor receptor-tyrosine kinase inhibitor (EGFR-TKI) treatment. Ann Surg Oncol 20 (Suppl 3): S545-S552, 2013.

9. Mukherjee S, Mazumdar M, Chakraborty S, Manna A, Saha S, Khan P, Bhattacharjee P, Guha D, Adhikary A, Mukhjerjee S and Das T: Curcumin inhibits breast cancer stem cell migration by amplifying the E-cadherin/ $\beta$-catenin negative feedback loop. Stem Cell Res Ther 5: 116, 2014.

10. Harrington K, Berrier A, Robinson M, et al: Randomised Phase II study of oral lapatinib combined with chemoradiotherapy in patients with advanced squamous cell carcinoma of the head and neck: Rationale for future randomised trials in human papilloma virus-negative disease. Eur J Cancer 49: 1609-1618, 2013

11. Tsai JH and Yang J: Epithelial-mesenchymal plasticity in carcinoma metastasis. Genes Dev 27: 2192-2206, 2013.

12. Umbreit C, Flanjak J, Weiss C, Erben P, Aderhold C, Faber A, Stern-Straeter J, Hoermann K and Schultz JD: Incomplete epithelial-mesenchymal transition in p16-positive squamous cell carcinoma cells correlates with $\beta$-catenin expression. Anticancer Res 34: 7061-7069, 2014.

13. Krisanaprakornkit S and Iamaroon A: Epithelial-mesenchymal transition in oral squamous cell carcinoma. ISRN Oncol 2012: 681469, 2012

14. Hay ED: The mesenchymal cell, its role in the embryo and the remarkable signalling mechanisms that create it. Dev Dyn 233: 706-720, 2005 .

15. Huber MA, Kraut N and Beug H: Molecular requirements for epithelial-mesenchymal transition during tumour progression. Curr Opin Cell Biol 17: 548-558, 2005.

16. Lee JM, Dedhar S, Kalluri R and Thompson EW: The epithelial-mesenchymal transition: New insights in signalling, development and disease. J Cell Biol 172: 973-981, 2006.

17. Kaimal R, Aljumaily R, Tressel SL, et al: Selective blockade of matrix metalloprotease-14 with a monoclonal antibody abrogates invasion, angiogenesis and tumour growth in ovarian cancer. Cancer Res 73: 2457-2467, 2013.

18. Zarrabi K, Dufour A, Li J, Kuscu C, Pulkoski-Gross A, Zhi J, $\mathrm{Hu}$ Y, Sampson NS, Zucker S and Cao J: Inhibition of matrix metalloproteinase 14 (MMP-14)-mediated cancer cell migration. J Biol Chem 286: 33167-33177, 2011.

19. Umbreit C, Aderhold C, Faber A, Sommer JU, Sauter A, Hofheinz RD, Stern-Sträter J, Hoermann K and Schultz JD: Unexpected alteration of $\beta$-catenin and c-KIT expression by 5-FU and docetaxel in p16-positive squamous cell carcinoma compared to HPV-negative HNSCC cells in vitro. Anticancer Res 33: 2457-2465, 2013.

20. Tang YL, Fan YL, Jiang J, Li KD, Zheng M, Chen W, Ma XR, Geng N, Chen QM, Chen Y and Liang XH: C-kit induces epithelial-mesenchymal transition and contributes to salivary adenoid cystic cancer progression. Oncotarget 5: 1491-1501, 2014.

21. Al Moustafa AE, Achkhar A and Yasmeen A: EGF-receptor signalling and epithelial-mesenchymal transition in human carcinomas. Front Biosci (Schol Ed) 4: 671-684, 2012.

22. Chang JY, Wright JM and Svoboda KK: Signall transduction pathways involved in epithelial-mesenchymal transition in oral cancer compared with other cancers. Cells Tissues Organs 185: 40-47, 2007.

23. Yang ZC, Yi MJ, Ran N, Wang C, Fu P, Feng XY, Xu L and $\mathrm{Qu} \mathrm{ZH}$ : Transforming growth factor- $\beta 1$ induces bronchial epithelial cells to mesenchymal transition by activating the Snail pathway and promotes airway remodeling in asthma. Mol Med Rep 8: 1663-1668, 2013. 
24. Acevedo VD, Gangula RD, Freeman KW, Li R, Zhang Y, Wang F, Ayala GE, Peterson LE, Ittmann M and Spencer DM: Inducible FGFR-1 activation leads to irreversible prostate adenocarcinoma and an epithelial-to-mesenchymal transition. Cancer Cell 12: 559-571, 2007.

25. GuoF, Parker Kerrigan BC, Yang D, Hu L, Shmulevich I, Sood AK, Xue F and Zhang W: Post-transcriptional regulatory network of epithelial-to-mesenchymal and mesenchymal-to-epithelial transitions. J Hematol Oncol 7: 19, 2014.

26. Brabletz T, Hlubek F, Spaderna S, Schmalhofer O, Hiendlmeyer E, Jung A and Kirchner T: Invasion and metastasis in colorectal cancer: Epithelial-mesenchymal transition, mesenchymal-epithelial transition, stem cells and beta-catenin. Cells Tissues Organs 179: 56-65, 2005.

27. Brabletz T, Jung A, Reu S, Porzner M, Hlubek F, Kunz-Schughart LA, Knuechel R and Kirchner T: Variable beta-catenin expression in colorectal cancers indicates tumour progression driven by the tumour environment. Proc Natl Acad Sci USA 98: 10356-10361, 2001.

28. Hajra KM and Fearon ER: Cadherin and catenin alterations in human cancer. Genes Chromosomes Cancer 34: 255-268, 2002

29. Schultz JD, Sommer JU, Hoedt S, Erben P, Hofheinz RD, Faber A, Thorn C, Hörmann K and Sauter A: Chemotherapeutic alteration of $\beta$-catenin and c-kit expression by imatinib in p16-positive squamous cell carcinoma compared to HPV-negative HNSCC cells in vitro. Oncol Rep 27: 270-280, 2012.

30. Brabletz T: The Rudolf Virchow Prize 2001. The role of the oncoprotein beta-catenin in the progression of colorectal cancers. Verh Dtsch Ges Pathol 85: 243-249, 2001 (In German).

31. Zhang $X$ and Hao J: Development of anticancer agents targeting the Wnt/ $\beta$-catenin signaling. Am J Cancer Res 5: 2344-2360, 2015 (Review).

32. Maseki S, Ijichi K, Tanaka H, Fujii M, Hasegawa Y, Ogawa T, Murakami S, Kondo E and Nakanishi H: Acquisition of EMT phenotype in the gefitinib-resistant cells of a head and neck squamous cell carcinoma cell line through Akt/GSK-3ß/snail signallling pathway. Br J Cancer 106: 1196-1204, 2012.

33. Iwatsuki M, Mimori K, Yokobori T, Ishi H, Beppu T, Nakamori S, Baba $\mathrm{H}$ and Mori M: Epithelial-mesenchymal transition in cancer development and its clinical significance. Cancer Sci 101: 293-299, 2010

34. Kajiyama H, Shibata K, Terauchi M, Yamashita M, Ino K, Nawa A and Kikkawa F: Chemoresistance to paclitaxel induces epithelial-mesenchymal transition and enhances metastatic potential for epithelial ovarian carcinoma cells. Int J Oncol 31 : 277-283, 2007.

35. Shah AN, Summy JM, Zhang J, Park SI, Parikh NU and Gallick GE: Development and characterization of gemcitabine-resistant pancreatic tumour cells. Ann Surg Oncol 14: 3629-3637, 2007.

36. Vig N, Mackenzie IC and Biddle A: Phenotypic plasticity and epithelial-to-mesenchymal transition in the behaviour and therapeutic response of oral squamous cell carcinoma. J Oral Pathol Med 44: 649-655, 2015

37. Leemans CR, Braakhuis BJ and Brakenhoff RH: The molecular biology of head and neck cancer. Nat Rev Cancer 11: 9-22, 2011.

38. Klussmann JP, Preuss SF and Speel EJ: Human papillomavirus and cancer of the oropharynx. Molecular interaction and clinical implications. HNO 57: 113-122, 2009 (In German).

39. Scanlon CS, Van Tubergen EA, Inglehart RC and D'Silva NJ: Biomarkers of epithelial-mesenchymal transition in squamous cell carcinoma. J Dent Res 92: 114-121, 2013.
40. Koontongkaew S: The tumour microenvironment contribution to development, growth, invasion and metastasis of head and neck squamous cell carcinomas. J Cancer 4: 66-83, 2013.

41. Seiki M: Membrane-type 1 matrix metalloproteinase: A key enzyme for tumour invasion. Cancer Lett 194: 1-11, 2003.

42. Schultz JD, Muhlheim K, Erben P, et al. Chemotherapeutic alteration of VEGF-/PDGF- and PDGF-R $\alpha / \beta$ expression by imatinib in HPV-transformed squamous cell carcinoma compared to HPV-negative HNSCC in vitro. Oncology Reports 26: 1099-1109, 2011.

43. Cervantes-AriasA,PangLY and ArgyleDJ:Epithelial-mesenchymal transition as a fundamental mechanism underlying the cancer phenotype. Vet Comp Oncol 11: 169-184, 2013.

44. Lamouille S, Xu J and Derynck R: Molecular mechanisms of epithelial-mesenchymal transition. Nat Rev Mol Cell Biol 15: 178-196, 2014

45. Housman G, Byler S, Heerboth S, Lapinska K, Longacre M, Snyder N and Sarkar S: Drug resistance in cancer: An overview. Cancers (Basel) 6: 1769-1792, 2014.

46. Rodrigues IS, Lavorato-Rocha AM, de M Maia B, Stiepcich MM, de Carvalho FM, Baiocchi G, Soares FA and Rocha RM: Epithelial-mesenchymal transition-like events in vulvar cancer and its relation with HPV. Br J Cancer 109: 184-194, 2013

47. Richter P, Umbreit C, Franz M, Berndt A, Grimm S, Uecker A, Böhmer FD, Kosmehl $\mathrm{H}$ and Berndt A: EGF/TGF $\beta 1$ co-stimulation of oral squamous cell carcinoma cells causes an epithelial-mesenchymal transition cell phenotype expressing laminin 332. J Oral Pathol Med 40: 46-54, 2011.

48. Lee CG, McCarthy S, Gruidl M, Timme C and Yeatman TJ: MicroRNA-147 induces a mesenchymal-to-epithelial transition (MET) and reverses EGFR inhibitor resistance. PLoS One 9: e84597, 2014

49. Valenta T, Hausmann $\mathrm{G}$ and Basler $\mathrm{K}$ : The many faces and functions of $\beta$-catenin. EMBO J 31: 2714-2736, 2012.

50. Sahu N and Grandis JR: New advances in molecular approaches to head and neck squamous cell carcinoma. Anticancer Drugs 22: 656-664, 2011.

51. Smilek P, Neuwirthova J, Jarkovsky J, Dusek L, Rottenberg J, Kostrica R, Srovnal J, Hajduch M, Drabek J and Klozar J: Epidermal growth factor receptor (EGFR) expression and mutations in the EGFR signalling pathway in correlation with anti-EGFR therapy in head and neck squamous cell carcinomas. Neoplasma 59: 508-515, 2012.

52. Ciardiello F and Tortora G: Epidermal growth factor receptor (EGFR) as a target in cancer therapy: Understanding the role of receptor expression and other molecular determinants that could influence the response to anti-EGFR drugs. Eur J Cancer 39: $1348-1354,2003$

53. Fumagalli I, Dugue D, Bibault JE, Clémenson C, Vozenin MC, Mondini M and Deutsch E: Cytotoxic effect of lapatinib is restricted to human papillomavirus-positive head and neck squamous cell carcinoma cell lines. Onco Targets Ther 8: 335-345, 2015.

54. Thiery JP and Sleeman JP: Complex networks orchestrate epithelial-mesenchymal transitions. Nat Rev Mol Cell Biol 7: 131-142, 2006.

55. Lamouille S, Subramanyam D, Blelloch $\mathrm{R}$ and Derynck R: Regulation of epithelial-mesenchymal and mesenchymal-epithelial transitions by microRNAs. Curr Opin Cell Biol 25: 200-207, 2013. 